Original Article

\title{
Early Marriages leads to low self-esteem of young girls

${ }^{3}$ Aga Khan University

${ }^{4}$ Patel Hospital Karachi

\begin{abstract}
Objective The focus of this study is to be acquainted with the level of trust and reliance regarding reproductive health concerns among early married females. Introduction Many females around the globe are subjected to early marriage with immature minds and bodies, and they are forced to shoulder heavy duties, early pregnancies, harsh family behaviors, family disputes, behavioral problems and understanding problems. Early pregnancies and other health problems have a great impact on their self-esteem, confidence level and their trust on elders to share their problems. When females are married at early age, they are not only deprived of their education but they are also not aware of the health consequences and their solutions. Methods: A cross-sectional observational study was conducted in Karachi and data was collected through detailed interview among 100 subjects (married and unmarried females). Results $41.98 \%$ of the unmarried girls relied on lady doctors for their reproductive health problems whereas $37.50 \%$ of married girls approached mothers and few talked to lady doctors while most of them were not sharing theirs obstacles with anyone. Conclusion It is concluded that females in their teens before marriage had normal self-esteem and courage to share their problems, on the other hand early marriages were found to cause a decline in their levels of self-esteem due to domestic pressures, less social buck up, fears of inlaws and husbands.
\end{abstract}

\section{KEYWORDS}

Early Marriage, Self-esteem, Depression, domestic pressure, reproductive health

\section{INTRODUCTION}

In South Asian region trend of marrying females at very early age is high, which is one of the major cause of domestic violence, physical burdens and health consequences (UNICEF; 2005). Young married girls are not aware of their responsibilities, nor do they have any idea of upcoming health consequences related to their pregnancy, weak immune system, and frequent sexual meet-ups with spouse risking their health towards other STDs (Ahmed; 2014), According to a report of WHO; approximately 4.4 million young females around the globe are victims of induced abortions mostly reported in females of age 15-24 years in response to early marriage. Over the decades marriages at early age without the consent of girls is frequently seen. According to several research studies married young girls are not familiar with health consequences moreover they are also not allowed to share whatever they suffer regarding their health which in turn decrease down their level of confidence and reliability on others to share problems (Campbell; 1993). Such females are even exposed to have high infant mortality rates, weaker health and poor self-esteem (UNICEF; 2005). It has been found in a research study that males spouse reported higher self-esteem however on their social part there is not much difference found in levels of both genders (Shackelford; 2001). Marriage in teenagers shall not be practiced as it has some adverse effects on both males and female's health however females are much prone to be at high risk of severe health consequences like low self-esteem, depression, and many bodily associated burdens (Ahmed; 2014). Females are left neglected thus suppressing their moral and confidence to share their views and leaving them to experience either major depressive disorder or diagnosed symptoms. Such symptoms include isolation, mood swings, aggressiveness, crying spells, general unhappiness, loss of concentration and lethargy (Whitton; 2007).

Females have low self-esteem as compared to male and these low and high aspects have a vivid impact on their cognitive and social behaviors which may results in deviant changes in their moods and attitudes (Bolognini; 1996). While another study also claims that females are mostly interdependent and they tend to make more relations socially and can mingle with surroundings around whereas males are more conscious to be different and to be peculiar from others, this acuity of individuals about themselves alter the level of self-esteem in both gender (Brown; 1990). Relations are basic human needs to fondle and care for, self-esteem and relation go hand in hand if there will be high self-esteem more will be the relation appear to be less controversial and there will be freedom of speech among individuals to share their thoughts and words with each other when there will be a friendly dealing among the two (Voss; 1999). Unmarried females are found to have normal self-esteem as they do not find such peer pressures of in-laws or any dominating behavior over them. They are more free or independent as compared to married females to share their health related problems with their mothers (Srivastava; 2013). It is assayed that married females with negative self-evaluation were reporting depression as they though they are not getting enough care and respect from their partners which in turn made them to feel low or negative thus affecting their esteems. Moreover social support which can be from outside family, friends or other relation helped those female to raise their esteem and to put them on a bit positivity. Friendship is mostly observed in married couples and it is the most prominent cause of a better understanding and good self-esteem of both partners.

Similarly females or child brides when interact with new individuals after marriage are unable to deal them psychologically and they for being in their teens are not valued much which is mostly due to the bad behaviors shown from in-laws towards them thus leading them to lower self-esteem, increasing their risk of clinical depression which on extreme aspect can cause suicidal attempts. (Brown; 1986). Female adolescents are seems to be more dejected as once they reach puberty they are confined to homes with their outdoor activities reduced and due to social peer pressures. Under age marriage is another pressure cooker for girls along with frustration and depression. In a survey conducted in GAZA it was reported that almost $52 \%$ of early married females opted for suicide due to depression. Early married females due to low self-esteem and petite amount of friendly dealings are restricted from sharing their problems with anybody in surroundings and even if they face some severe health issues related to their reproductive life they refrain from sharing them with anyone but mother is thought to be a friend of girls in most communities of Pakistan (Afzal; 2008).

In many societies marrying females in early teens is considered as achievement in society and if this marriage is escorted by an early pregnancy then it is certified to a girl that she is some precious entity as she is a mother now but in between these religious, cultural and 
society norms, the fact of illiteracy is forgotten which is necessary part for a girl life (UNICEF; 2005), the major objective behind present study is to explore the level of trust and reliance regarding reproductive health concerns among early married females.

\section{METHODOLOGY}

A cross-sectional observation study was designed which included sample size of 100 females both married and unmarried subjects of Karachi. Data was analyzed using SPSS version 21.0.

\section{RESULTS}

From our study we found that $41.9 \%$ unmarried girls have high reliance on lady doctors related to their health issues whereas $27.16 \%$ rely on their mothers and $1.23 \%$ approach midwives however $29.6 \%$ girl do not share it with any one. When same question was asked from early married females $37 \%$ were relying on their mothers, $29 \%$ were consulting lady doctors and $33.3 \%$ did not bother to tell anyone.

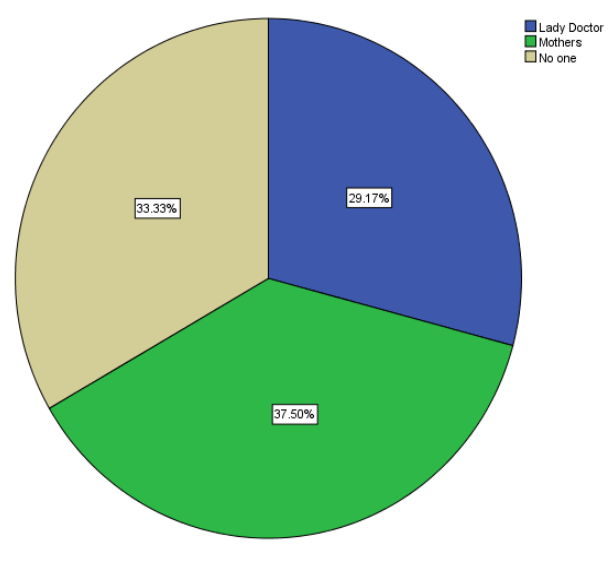

Figure 1. Showing the health concerns of unmarried girls related to their health

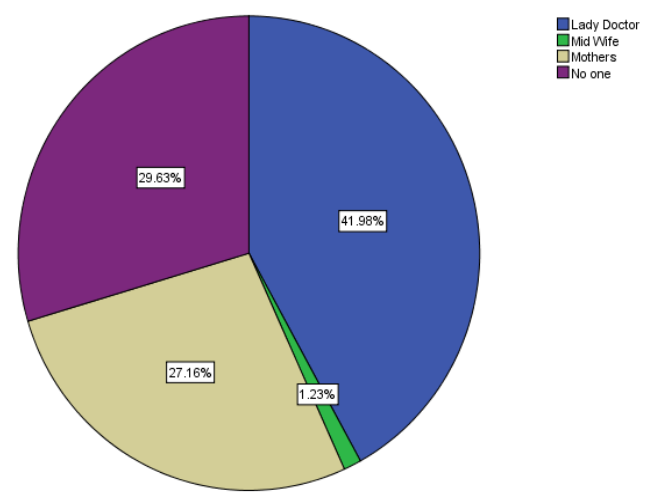

Figure 2. Shows the status of married females regarding their health concerns

\section{CONCLUSION}

From views of married and unmarried females we concluded that those females who were not married reported normal self-esteem before marriage as they had the freedom to rely on their mothers whereas married females reported a decline in their self-esteem after marriage as they were not able to share their problem due to domestic pressures, fears of being neglected, and lack of social support from family and friends.

\section{DISCUSSION}

Activists or policymakers need to be in support of stopping child marriage as it has been in practices since many decades and many girls are pushed towards illness and violence. Still in many countries about $50 \%$ of females are married at age 18 and almost $70 \%$ are married by the age of 20. This ratio is much higher in sub Saharan region of Africa, south Asian countries like Nepal, India, Bangladesh, and Pakistan (Ahmed; 2014, Ahmed; 2013). The reason behind such practices is familial control over female's choices to marry, financial crisis, parent's fears about their child being sexually abused. Teenage girls needs to be educated and trained such practices are causing hindrances for care-workers to provide these girls sex education, reproductive issues awareness and general health services (Singh; 1996). People working in field of psychology and dealing with emotional disturbances reports that a girl married by very early age is more teary and depressed as she loses her childhood on the very $1^{\text {st }}$ hand and she is no more allowed to feel pleasure in the odd activities she uses to enjoy before as she is now shouldering heavy responsibilities being married. If a girl of age 13 less educated is married she is more likely to repeat the same to her daughter as she remains uneducated throughout her whole life and there is no trend of supporting such girls by the families of inlaws, such girls are exposed to domestic violence, sexual manipulation (UNICEF; 2005). Females in India are at higher risk of HIV and other infectious diseases as most of the young age early pregnancies are unplanned and there is no thought of birth control, where as in many Asian countries induced abortions are practiced due to age of the mother and if she somehow completes her pregnancy trimesters still there are chances of child death having major cause of poor neonatal health, improper care by mother due to lack of education, mother herself is susceptible to cervical cancers, vaginal tract disease (Santhya; 2008). Marital conflicts leaves a negative impact on interpersonal dealing of both gender leading to more fights, tensed situations which will trigger depressive symptoms to develop, causing the health of female to get worse and if this continue to be there she might adopt isolation and less social interaction (Whitton; 2007). Self-esteem has to do more with gender and psyche of an individual. Females are generally thought to be at low esteem whereas males have high self-esteem due to these reasons females are mostly observed to be involved in negative self-evaluation which restricts their social activities, presenting them less opportunities to make the most out of life and low confidence levels which is another obstacle in their communication skills regarding their health issues and education (Brown; 1986). Friendly relations and social support can make female happy and confident to grow in their life and to discover their strengths helping them to deal their matters wisely and constant support can help them to learn handling their health issues in a proper way by sharing it with their mothers or health care professional. In rural areas there should be some health care professional visits or awareness programs to teach girls about general health hygiene, sex education, reproductive issues, and ways to build their esteem, motivation and above all welcoming relation with spouse (Voss, 1999).

CONFLICT OF INTEREST

Authors declare no conflict of interest. 


\section{ACKNOWLEDGMENT}

We would like to acknowledge Saima Khan for her energies in reviewing limited literature and S. M. Tahir for assisting in data analysis software.

\section{REFERENCE}

1. Ahmed, S., Khan, A. Khan. S., \& Noushad, S. (2014). Early Marriage; a Root of Current Physiological and Psychosocial Health Burdens.

2. Campbell, J. D., \& Lavallee, L. F. (1993). Who am I? The role of self-concept confusion in understanding the behavior of people with low self-esteem. In Self-esteem (pp. 3-20). Springer US.

3. UNICEF. (2005). Early Marriage A Harmful Traditional Practice A Statistical Exploration 2005. UNICEF.

4. Shackelford, T. K. (2001). Self-esteem in marriage. Personality and Individual Differences, 30(3), 371-390.

5. Silberschmidt, M., \& Rasch, V. (2001). Adolescent girls, illegal abortions and "sugar-daddies" in Dar es Salaam: vulnerable victims and active social agents. Social science \& medicine, 52(12), 1815-1826.

6. Bolognini, M., Plancherel, B., Bettschart, W., \& Halfon, O. (1996). Self-esteem and mental health in early adolescence: Development and gender differences. Journal of adolescence, 19(3), 233-245.

7. Brown, G. W., Bifulco, A., Veiel, H. O. F., \& Andrews, B. (1990). Self-esteem and depression. Social psychiatry and psychiatric epidemiology, 25(5), 225-234.

8. Voss, K., Markiewicz, D., \& Doyle, A. B. (1999). Friendship, marriage and self-esteem. Journal of Social and Personal Relationships, 16(1), 103-122.

9. Brown, G. W., Andrews, B., Harris, T., Adler, Z., \& Bridge, L. (1986). Social support, self-esteem and depression. Psychological medicine, 16(04), 813-831.

10. Afzal, S., Rana, T. F., \& Mehmood, S. (2008). Determinants of depression in female adolescents and youth. Professional Med J, 15(1), 137-142.

11. Whitton, S. W., Olmos-Gallo, P. A., Stanley, S. M., Prado, L. M., Kline, G. H., St Peters, M., \& Markman, H. J. (2007). Depressive symptoms in early marriage: predictions from relationship confidence and negative marital interaction. Journal of Family Psychology, 21(2), 297.

12. Singh, S., \& Samara, R. (1996). Early marriage among women in developing countries. International family planning perspectives, 148-175.

13. Santhya, K. G., Jejeebhoy, S. J., \& Ghosh, S. (2008). Early marriage and sexual and reproductive health risks: Experiences of young women and men in Andhra Pradesh and Madhya Pradesh, India. Population Council.

14. Srivastava, N., \& Agarwal, S. (2013). Self Esteem Among Young Adults-A Comparative Study. International Journal of Humanities and Social Science Inventions, 2(3), 59-61.

15. Orr, D. P., Wilbrandt, M. L., Brack, C. J., Rauch, S. P., \& Ingersoll, G. M. (1989). Reported sexual behaviors and selfesteem among young adolescents. American Journal of Diseases of Children, 143(1), 86-90. 